\title{
Empirical application of car demand elasticity using SATURN
}

\author{
J. Wang ${ }^{1}$, H. Nguyen ${ }^{2}$ \& Q. Feng ${ }^{3}$ \\ ${ }^{I}$ Steer Davies Gleave, UK \\ ${ }^{2}$ Transport for London, UK \\ ${ }^{3}$ The Mouchel Group, UK
}

\begin{abstract}
This paper discusses the application of variable demand modelling using SATURN. A practical example, i.e. Merseyside Highway model, is presented to illustrate the effects with and without using elastic assignment. The Merseyside Highway Model has been constructed to support the development and assessment of a wide range of potential public transport, road improvement and land use development proposals in the Merseyside area, UK. The development of the future year highway model includes traffic growth to produce the future year matrices, and also the changes to the road networks to reflect the schemes tested. In order to test the robustness of the Merseyside highway scheme, fixed demand and variable demand assignments via travel cost elasticity have been tested with the results compared and discussed in this paper. The Power function is adopted as it has neutral effect on the trip lengths whilst the Exponential function might result in remarkable trips increase/reduction for shorter trips.

It is found that by ignoring the behaviour changes to the journey cost, the highway benefits tend to be over-estimated. It is suggested that using pivot-point estimates of elastic demand, it can bring the robustness to the scheme evaluation.
\end{abstract} Keywords: elasticity, fixed demand assignment, variable demand assignment.

\section{Introduction}

The Merseyside Highway Model has been constructed to support the development and assessment of a wide range of potential public transport, road improvement and land use development proposals in the Merseyside area. The development of the future year highway model includes traffic growth to 
produce the future year matrices, and also the changes to the road networks to reflect the schemes tested.

In order to test the robustness of the Merseyside highway scheme, fixed demand and variable demand assignments via travel cost elasticity have been tested with the results compared and discussed in this paper.

\section{Elasticity model}

According to UK's Department for Transport (DfT) WebTAG guidelines Unit 3 (DfT [1]), a variable demand model is required for the assignment stage to provide cost information to the demand model using an elastic approach.

"Elasticity model assumes that changes in the demand for travel between two points can be adequately estimated purely by the function of the change in costs between the two places" (DfT [1]).

The car journey time elasticity is therefore introduced to reflect the change of car trips in response to the change in journey time/cost. SATURN, the widely used road traffic modelling software package, provides the facility to generate induced/ suppressed traffic demand with respect to the change in transport costs (Vliet [2]).

Two frequently used functions to calculate journey time elasticity include the Power function, and Exponential function (Otuzar and Willumsen [3]). The power function assumes the proportional change in trips is the function of the proportional change in costs (eqn 1). However, the Exponential function assumes the proportional change in trips is the function of the absolute change in cost (eqn 2). As the Exponential function is with respect to the absolute change of cost, the resulting ratio of trip changes is not only the response to the cost change, but also to the original trip cost, such as the distance between zones $\mathrm{i}$ and $\mathrm{j}$.

$$
\begin{gathered}
\frac{T_{i j}}{T_{i j_{-} 0}}=\frac{C_{i j}{ }^{A}}{C_{i j_{-} 0}} \\
\frac{T_{i j}}{T_{i j_{-} 0}}=\exp \left\{B \times\left(C_{i j}-C_{i j_{-} 0}\right)\right\}
\end{gathered}
$$

where,

$T_{i j}-{ }^{0}$ the original trips between zones $\mathrm{i}$ and $\mathrm{j}$;

$T_{i j}$ the new trips between zones $\mathrm{i}$ and $\mathrm{j}$;

$C_{i j}{ }^{0}$ the original trips between zones $\mathrm{i}$ and $\mathrm{j}$;

$C_{i j}$ the new costs between zones $\mathrm{i}$ and $\mathrm{j}$;

A the elasticity value of the Power function, constant;

B the elasticity value of the Exponential function, constant.

As shown in Figure 1, the higher the absolute power value of $\mathrm{A}$ in the Power function, the steeper the curve of trips change ratio. As the power function is the 


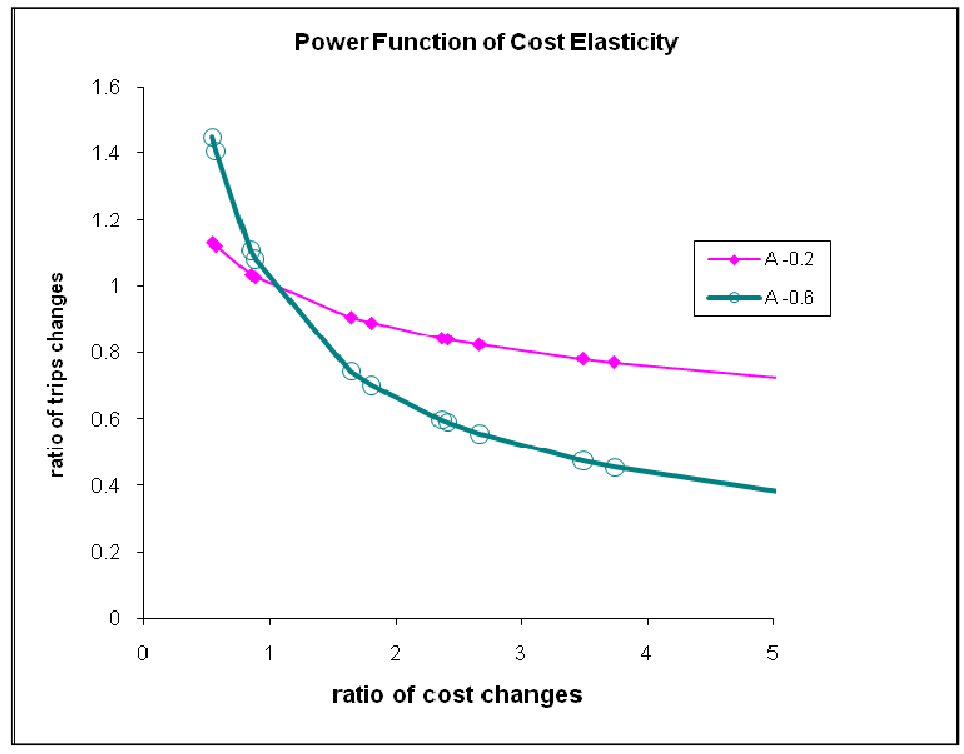

Figure 1: The Power function of cost elasticity.

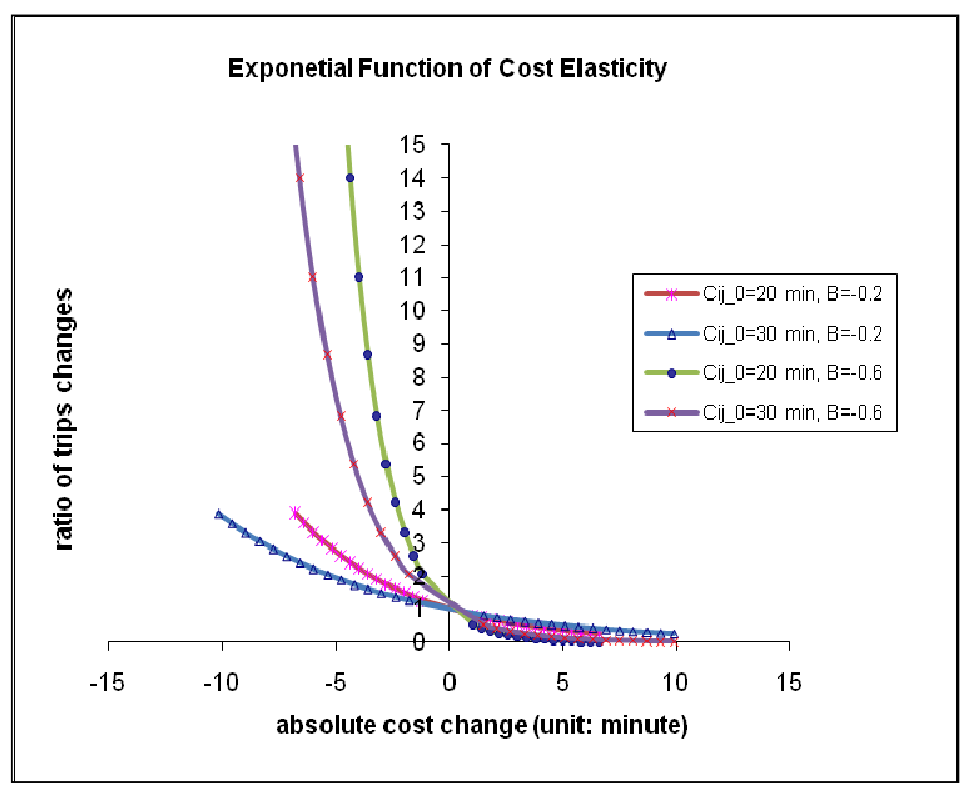

Figure 2: The exponential function of cost elasticity.

calculation based on the ratio the cost changes, the trip length has neutral effects on the trip demand.

However, as illustrated in Figure 2, both of the trip length and the elasticity value of $B$ contribute to the ratio of trip changes. With same elasticity values, 
shorter trips are more affected by the absolute of the change in trip length. For example, with B as -0.6 , a reduction of 5 minutes journey time would results in 14 times and 7 times trip growth for the original 20 minutes and 30 minutes trip length respectively. It makes sense that shorter journeys and longer journeys respond to the trip cost change differently. However, the extent of trip change ratio, e.g. 14 times trips growth when trip length is reduced from 20 minutes to 15 minutes, is not very comfortable.

Therefore, to avoid the markedly change in the trip demand to varied trip lengths, the power function is adopted for the Merseyside study.

\section{The development of variable demand matrix in the Merseyside study}

\subsection{Background}

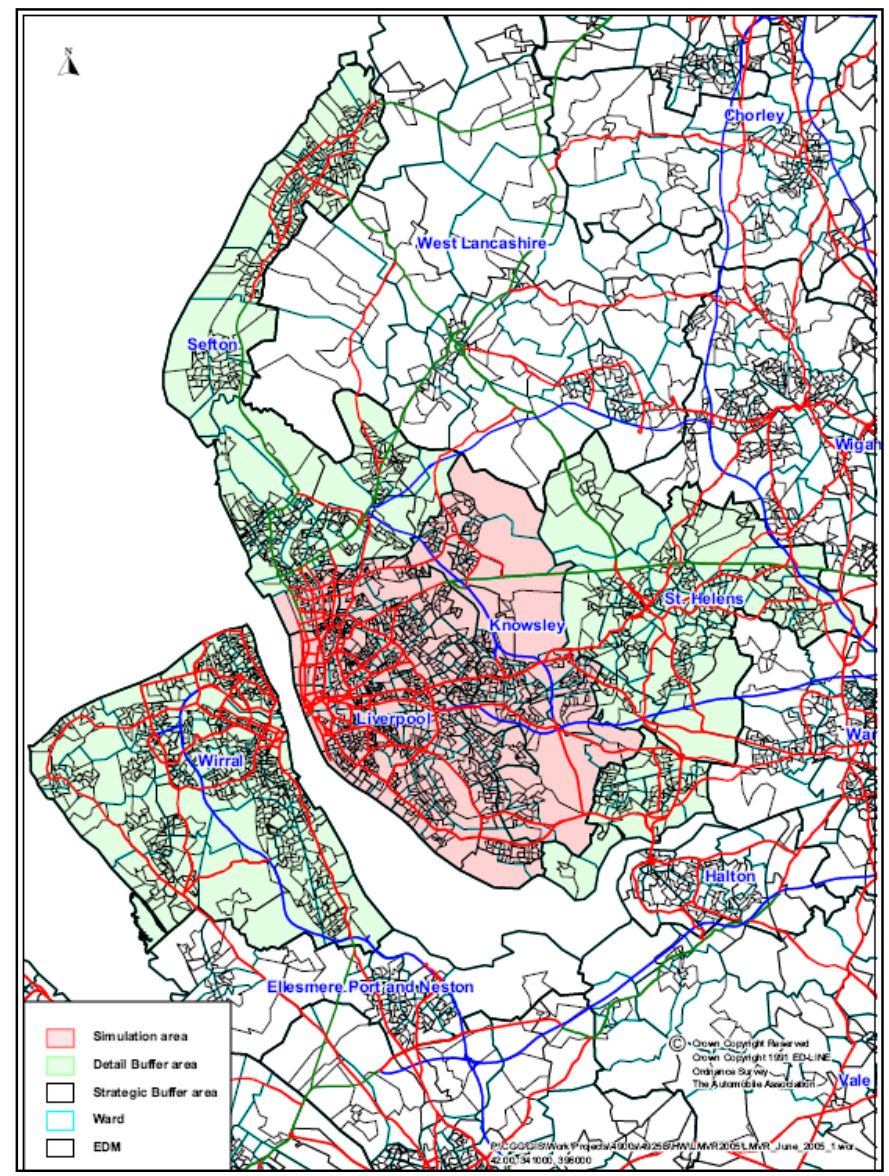

Figure 3: $\quad$ Merseyside study area, UK. 
The Merseyside highway model's network covers all of Great Britain, having the following features (Figure 3):

- A detailed simulation network of the Liverpool and Knowsley areas;

- A detailed buffer network for the rest of Merseyside;

- A motorway/primary route buffer network of the North West region; and

- A skeletal network of feeder routes for the rest of the UK.

\subsection{The Merseyside highway scheme and matrix development}

The proposed highway scheme includes a much better defined north-south routeing in Liverpool and an improved linkage between Wavertree Road and Islington/New Islington for trips to/from Liverpool City Centre north.

In order to test the robustness of the above-mentioned Merseyside highway scheme, fixed demand and elastic demand are assigned to the Do Something (i.e. with the highway scheme) and Do Minimum (i.e. without the highway scheme) future networks.

In this study, the fixed demand assumed the future matrix does not respond to the network changes or congestion level in the future year therefore simply as a resultant of the TEMPRO growth over years as predicted by DfT [4].

The elastic demand, however, takes into account that trips respond to the change of journey cost causing by the future congestion level and the highway scheme. Therefore, the high congestion level in the future will suppress the trips, whilst the reduction of certain zone pair journey time due to the highway scheme will induce more trips.

Being successfully calibrated/validated in the base year 2008 (SDG [5]), the mechanism of pivot-point estimate changes relative to base matrix is applied here. This is in accordance to the WebTAG (DfT [1]) that in order to preserve the complexities of the base matrix, pivot-point models "use cost changes to estimate the changes in the number of trips from a base matrix".

By using the WebTag suggested time elasticity values at the starting points (DfT [1]), the values presented in the table below are derived by combining all trip purposes for different time periods in the Merseyside study area. It shows that the off-peak has a relatively lower elasticity to the journey cost than the other two periods.

Table 1: Journey cost elasticity values in the Merseyside study.

\begin{tabular}{|l|r|c|}
\hline \multirow{2}{*}{ Time Period } & \multicolumn{2}{|c|}{ Journey Cost Elasticity } \\
\cline { 2 - 3 } & Value & Description \\
\hline AM Peak & -0.72 & High modal competition including time-switching \\
\hline Off Peak & -0.49 & High modal competition \\
\hline PM Peak & -0.70 & High modal competition including time-switching \\
\hline
\end{tabular}


As presented in Table 2, with less elasticity in the off-peak, the percentage of trips change is lower than the other two peaks, i.e. AM and PM. With congested level being high in 2025, it is found that generally the trip reductions to the fixed demand in the elasticity matrices are higher than those in year 2010. The trips differences between DS and DM, however, are at a similar level.

The trip suppressions in the year 2025 for AM and PM periods are both at the level of $7 \%$. This may reflect the fact that congestion in the Liverpool and surrounding area in 2025 is widespread in the network, thus people might choose other modes such as PT rather than simply re-routing the car trips.

Table 2: $\quad$ The percentage of reduced trips - Elastic Matrix versus the Fixed Demand Matrix.

\begin{tabular}{|l|l|l|l|}
\hline $\begin{array}{l}\text { Elastic Matrix to Fixed } \\
\text { Demand Matrix } \\
\text { Reduced Trips \% }\end{array}$ & Scheme & $\mathbf{2 0 1 0}$ & $\mathbf{2 0 2 5}$ \\
\hline AM Peak & Do Minimum & $3 \%$ & $7 \%$ \\
\cline { 2 - 4 } & Do Something & $3 \%$ & $7 \%$ \\
\hline Off Peak & Do Minimum & $1 \%$ & $2 \%$ \\
\cline { 2 - 4 } & Do Something & $1 \%$ & $2 \%$ \\
\hline \multirow{2}{*}{ PM Peak } & Do Minimum & $3 \%$ & $7 \%$ \\
\cline { 2 - 4 } & Do Something & $3 \%$ & $7 \%$ \\
\hline
\end{tabular}

\subsection{Model assignment and highway scheme evaluation}

By assigning the fixed and elastic demand matrices to the future highway networks, the benefits of road schemes are evaluated using DfT's TUBA, the transport economic appraisal software. It is found that with elastic assignments, the benefits are less than the fixed demand benefits by 9\% (SDG [6]).

It suggests that for this study where congestion is the key drive for the trip suppression in the future year, the overall benefits might be slightly overestimated using fix demand approach.

\section{Conclusions}

This paper discusses the application of variable demand modelling using SATURN. The Power function is adopted as it has neutral effect on the trip lengths whilst the Exponential function might result in remarkable trips increase/reduction for shorter trips. 
A practical example is presented to illustrate the effects with and without using elastic assignment. It is found that by ignoring the behaviour changes to the journey cost, the highway benefits tend to be over-estimated. It is suggested that using pivot-point estimates of elastic demand, it can bring the robustness to the scheme evaluation.

\section{References}

[1] DfT WebTAG, www.dft.gov.uk/webtag/

[2] Vliet, D. V, Assignment - The Role of SATEASY/ SATAll (Chapter 7). SATURN Manual V10.9, 2010

[3] Otuzar, J. \& Willumsen, L., Modelling Transport, John Wiley \& Sons, 2001

[4] DfT TEMPRO, www.dft.gov.uk/tempro

[5] SDG, Merseyside Highway Model LMVR report,2009

[6] SDG, Hall Lane Future Year Model Development,2009 